\title{
Model for evaluating the electric power output of Pressure Retarded Osmosis generation plants
}

\author{
Mario Llamas-Rivas, Alejandro Pizano-Martínez, Claudio R. Fuerte-Esquivel, Luis R. Merchan-Villalba \\ and Víctor J. Gutiérrez-Martínez
}

\begin{abstract}
In this work a mathematical model is assembled to evaluate the electric complex power and electric current output of pressure retarded osmosis (PRO)based generation plants. Unlike other works already reported in the literature, the assembled model allows performing that evaluation in the $a b c$ reference frame based on the salinity concentrations of the salty and fresh water bodies entering the membrane modules and the phasor voltages at the terminals of the generation plant. The induction generator is selected as the power transductor. The assembled model also collects main phenomena affecting the PRO process efficiency: internal concentration polarization, external concentration polarization and spatial variations. A numerical example is presented where the model is used to evaluate the electric complex power output of the PRO generation plant. The numerical results obtained suggest that reactive power compensation may be needed for the selected power transductor. These results also confirm that the main phenomena affecting the PRO process efficiency substantially affect the active power production, but not the reactive power consumption. In this way, the assembled model may be used to analyse the steady state performance of electric networks under the integration of PRO generation plants.
\end{abstract}

Keywords - Electric induction generator, electric power generation evaluation, pressure retarded osmosis, PRO generation plant, salinity gradient.

\section{INTRODUCTION}

$\mathrm{T}_{\mathrm{i}}^{\mathrm{s}} \mathrm{dan}$ he demand for electric energy has importantly increased in the last decades due to population growth and economic development, which has unlaced a

Manuscript received 16 March; accepted 27 March; published 12 May, 2020. This is an open access article distributed under the terms of the Creative Commons Attribution 4.0 licence (CC BY http://creativecommons.org/licenses/by/4.0/). This article has been subject to single-blind peer review by a minimum of two reviewers. The authors acknowledge the sponsor and financial support provided by the CEMIE-O under project SENER-CONACyT 249795, as well as the concurrent support provided by the Universidad de Guanajuato and the Universidad Michoacana de San Nicolás de Hidalgo for the realization of this work. M. Llamas-Rivas, A. Pizano-Martínez, L.R. Merchan-Villalba and V.J. Gutiérrez-Martínez are with the Dept. of Electrical Engineering, Universidad of Guanajuato, 58030 Salamanca, México (email: m.llamasrivas@ugto.mx; apizano@ugto.mx; lr.merchanvillalba@ugto.mx; vj.gutierrez@ugto.mx). C.R. Fuerte-Esquivel is with the Faculty of Electrical Engineering,Universidad Michoacana de San Nicolás de Hidalgo, 58030 Morelia,México (email: cfuerte@umich.mx).

Digital Object Identifier https://doi.org/10.36688/imej.3.1-10

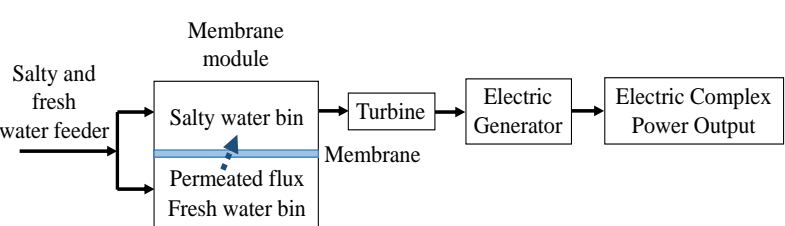

Fig. 1. Generic representation of a PRO plant.

faster consumption of fossil fuels and an increase of greenhouse gas emissions. At the same time, our planet is experiencing an undesirable climatic change and the depletion of the non-renewable energy resources is a global concern [1,2]. These concerns and the emerging energy technologies provide more than enough incentives to attempt reducing the consumption of fossil fuels and to increase the electric power production based on clean, green and renewable energy sources [3].

The oceans are one of such friendly energy sources and can provide vast amounts of energy for electric power production based on different mechanisms. One of those mechanisms is the pressure retarded osmosis (PRO) pioneered by Loeb [4], with a worldwide theoretical potential around of $1650 \mathrm{TWh} / \mathrm{y}$ [5]. In order to recover energy from the PRO mechanism, in the PRO-based power generation plants fresh (feed) and salty (drawn) water bodies are pumped into a membrane module, where the fresh and salty water bins are separated by a membrane permeable to water but not to salt. A generic representation of a PRO plant is given in Fig. 1. Due to the osmotic pressure difference produced by the salinity gradient between the two water bodies, a permeated flux of fresh water is produced toward the already pressurized bin of salty water. The flux equivalent to the permeated flux is the input of a turbine-electric generator system to produce electric power, (see Fig. 1) [6].

The evaluation of the energy extractable from the PRO process and its feasibility for electric power production are subjects of much importance under research [7]. In order to aid that evaluation, models describing the energy recovery from the PRO process have been developed. In this regard, the permeated flux and the electrical power production can be estimated from an ideal model [8]. That model, however, yields a substantial overestimation of the 
power production. This is because the efficiencies of the different generation plant components, concentration polarization and spatial variations phenomena are neglected [7]. These phenomena importantly decrease the salinity gradient, the permeated flux and thus the electric power production.

The polarization refers to the concentration of salty and fresh water nearby the membrane surfaces, reducing the effective salinity gradient and is considered in the models presented in $[5,6,7,9,10]$. In these models, however, the spatial variations phenomena are still neglected.

The spatial variations refer to the flow rate, friction losses and salt concentration changes along the membrane module. These effects along with the concentration polarization and PRO generation plant component efficiencies have been considered in the model proposed in $[11,12]$. The accuracy of the model for evaluating the permeated flux and power density in the membrane module proposed in these latter works has been verified in [13]. All the aforementioned models provide a step toward the accurate evaluation of the active electric power extractable from the PRO mechanism and provide insights to improve the salinity gradient energy exploitation. Though, these models provide such evaluation in terms only of the PRO process variables and generation plant components efficiencies.

Due to the potential feasibility of considering PRO generation plants for electrical power production, studying the effects on the electric network response and operation caused by its integration is an inevitable task. For that purpose, a suitable model of the PRO generation plant should provide not only an estimation of the complex (both active and reactive) power output in terms of the PRO process variables and system component efficiencies, but also should be explicitly in terms of the phasor voltage at the low voltage side of the coupling transformer (interface with the power network). These features are not addressed by the models reported in the existing literature.

Accordingly, the proposal in this paper consists of assembling a model for estimating the complex power output of the generation plant in terms of the PRO process variables, the hydraulic system component efficiencies and the phasor voltage at the low voltage side of the coupling transformer. For this purpose, the model reported in [11,12] is adopted and extended to consider a detailed model of the electrical generator, instead of considering its efficiency only. The proposal is developed in detail in the rest of this paper.

\section{PRO GENERATION PLANT COMPONENT MODELS}

The PRO generation plant is mainly composed of the membrane module, the hydraulic system, the turbine and the electric generator. The models of these components are provided as described below (see Fig. 1).

Firstly, following the proposals reported in [11,12], the model for evaluating the net power output $P_{\text {net }}$ of the

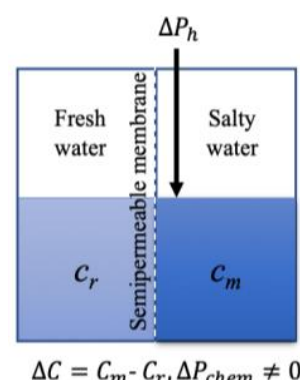

Fig. 2. Membrane module.

membrane modules is presented. For this purpose, a rough evaluation of the total power output of the membrane modules $P_{i d}$ is initially obtained from the ideal model given in Section II.A. The inputs of this model are the hydraulic pressure $\Delta P_{h}$ applied at the salty water bin inlet and the salinity gradient $\Delta C$ existing between the salty and fresh water bodies, with their values considered constant along the membrane modules.

Then, that ideal power output model is extended to consider the changes in the values of these inputs produced by the concentration polarization and spatial variations phenomena, as described in Sections II.B and II.C, respectively. The improvement of the ideal power output model is completed in Section II.D, where the hydraulic system losses are considered to finally obtain a more detailed model that allows a more accurate evaluation of the net power output $P_{\text {net }}$ of the membrane modules.

Secondly, the model of the turbine that converts the power output of the membrane modules into mechanical power $P_{\text {mech }}$ is provided in Section II.E. Lastly, a detailed model of the asynchronous induction generator that transduces the mechanical power $P_{\text {mech }}$ into three-phase complex power $S_{3 \phi}$ considering the machine line-to-line phasor voltages $V_{a b c}$ is given in Section II.F.

\section{A. Membrane modules ideal power output model}

The salty and fresh water bodies are pumped into the membrane module, where the PRO process is performed and the salinity gradient power can be extracted, as follows.

Fig. 2 shows a module where the salty and fresh water bins are separated by a semipermeable membrane (permeable to the water but not to salt). The salinity concentrations of the fresh and salty water at the membrane module inlet are $C_{r}$ and $C_{m}$, respectively. The corresponding ideally existing salinity gradient inside the whole membrane module is given by $\Delta C=\left(C_{m}-C_{r}\right)$.

The salinity gradient $\Delta C$ produces a chemical potential difference and the osmotic pressures $\pi_{r}$ and $\pi_{m}$ given by (1)-(2) appears. In this case, $R, T, M$ and $i_{j}($ for $j=r, m$ ) denotes the universal gas constant, the solution temperature, molar mass of the salt and the Van't Hoff factor, respectively. Since $\pi_{m}>\pi_{r}$, the resulting osmotic pressure difference $\Delta \pi$ given by (3) forces a fresh water flux $J_{w}$ through the membrane, as given by (4). In (4) $A$ is the membrane water permeability, whereas $\Delta P_{h}$ is the hydraulic pressure 
applied into the salty water bin to retard the osmotic process and recover the salinity gradient energy; thus, the permeated flux $J_{w}$ occurs at the pressure $\Delta P_{h}$. The power per unit of membrane area (power density) is given by (5). It is noted that the power density depends on the value of $\Delta P_{h}$. In order to maximize the power density and the salinity gradient energy recovering, the hydraulic pressure in the salty water bin is fixed at the value $\Delta P_{h}=\Delta \pi / 2$. The flow $Q_{m e m}$ of fresh water permeated through the membrane can be estimated from (6), where $A_{\text {mem }}$ is the total area of the membrane. Thus, when the total amount of membrane modules composing the PRO plant is $N_{\text {mod, the total flow }}$ $Q_{\text {mod }}$ is given by (7). Accordingly, the total power $P_{i d}$ ideally recovered at the membrane modules can be approximated from (8).

$$
\begin{gathered}
\pi_{r}=C_{r} R T i_{r} / M \\
\pi_{m}=C_{m} R T i_{m} / M \\
\Delta \pi=\pi_{m}-\pi_{r} \approx \Delta C R T i_{m} / M \\
J_{w}=A\left(\Delta \pi-\Delta P_{h}\right) \\
W=J_{w} \Delta P_{h} \\
Q_{m e m}=J_{w} A_{m e m} \\
Q_{\text {mod }}=Q_{m e m} N_{\text {mod }} \\
P_{i d}=\Delta P_{h} Q_{\text {mod }}=\Delta P_{h} A\left(\Delta \pi-\Delta P_{h}\right) A_{\text {mem }} N_{\text {mod }}
\end{gathered}
$$

The power given by (8) is the membrane modules power output and could be considered as the turbine-electric generator system input power. In (8), however, the concentration polarization and spatial variations are neglected, which may yield an overestimation of the PRO plant electric power output.

\section{B. Membrane modules power output model considering concentration polarization}

Across the membrane, not only the permeated flux $J_{w}$ occurs, but there is also a reverse flux of salt $J$ s. The latter is due to the membrane is not perfectly semipermeable. The flux $J_{w}$ across the membrane tends to reduce (resp. increase) the mass inside the fresh (resp. salty) water bin. On the other hand, the flux $J_{s}$ produces a decrement (resp. increment) of the salinity concentration of the salty (resp. fresh) water. As consequence, these fluxes yield an accumulation of fresh water and salt in regions surrounding the membrane active layer surfaces that separate the salty and fresh water bodies. This phenomenon is referred to as concentration polarization and produces an effective salinity concentration difference $\Delta C_{p o l}$ across the membrane active layer much lower than the one $\Delta C$ ideally existing between the fresh and salty water bodies.

The concentration difference $\Delta C_{p o l}$ can be estimated from (9) by assuming that the fresh and salty water salinity concentrations $C_{r}$ and $C_{m}$, respectively, remain constant beyond the region where the polarization occurs [13]. The numerator and denominator in (9), however, are functions $f(\cdot)$ and $g(\cdot)$ of the salinity concentration difference $\Delta C_{p o l}$ of interest. Thus, in order to formulate the assessment of $\Delta C_{p o l}$ as a root finding problem, (9) is readily re-written as the non-linear equation given in (10). The functions $f(\cdot)$ and $g(\cdot)$ are explicitly given by (11) and (12). The osmotic pressure difference $\Delta \pi$ pol given by (13) is used to formulate the permeated flux $J_{w}$ from (14). In (14) the hydraulic pressure $\Delta P_{h}$ must be considered as $\Delta P_{h}=\Delta \pi$ pol $/ 2$. The description of the structure parameter $S$, the boundary layer thickness $\delta_{j}$ and the salt diffusion coefficient $D_{j}$ (for $j=r, m$ ) in (11) and $(12)$ are detailed in $[11,12]$. In order to solve the non-linear equation (10), an initial condition of $\Delta C_{p o l}$ equal to $35 \mathrm{~g} / \mathrm{l}$ was considered in this work.

$$
\begin{gathered}
\Delta C_{p o l}=f\left(\Delta C_{p o l}\right) / g\left(\Delta C_{p o l}\right) \\
\Delta C_{p o l} \cdot g\left(\Delta C_{p o l}\right)-f\left(\Delta C_{p o l}\right)=0 \\
f\left(\Delta C_{p o l}\right)=C_{m} \exp \left(\frac{-J_{w} \delta_{m}}{D_{m}}\right)-C_{r} \exp \left(\frac{J_{w}\left(\delta_{r}+S\right)}{D_{r}}\right) \\
g\left(\Delta C_{p o l}\right)=1-\frac{B}{J_{w}}\left[\exp \left(\frac{-J_{w} \delta_{m}}{D_{m}}\right)-\exp \left(\frac{J_{w}\left(\delta_{r}+S\right.}{D_{r}}\right)\right] \\
\Delta \pi_{p o l} \approx \Delta C_{p o l} R T i_{m} / M \\
J_{w}=A\left(\Delta \pi_{p o l}-\Delta P_{h}\right)
\end{gathered}
$$

Since $\Delta C_{p o l}<\Delta C$, the osmotic pressure difference $\Delta \pi$ pol and fresh water permeated flux $J_{w}$ are lower than those provided by the ideal model, as can be inferred by comparing (13) and (14) with (3) and (4), respectively. Thus, the power output of the total amount $N_{\text {mod }}$ of membrane modules also decreases and can be formulated based on (8) by considering the flux $J_{w}$ provided by (14), as given by (15). Complementarily, the reverse salt flux $J_{s}$ can be evaluated from (16), where $B$ represents the salt permeability coefficient.

$$
\begin{gathered}
P_{p o l}=\Delta P_{h} A\left(\Delta \pi_{p o l}-\Delta P_{h}\right) A_{m e m} N_{m o d} \\
J_{s}=B \Delta C_{p o l}
\end{gathered}
$$




\section{Membrane modules power output model considering spatial variations}

The longer the membrane is, higher the mass transfer produced by the fluxes $J_{w}$ and $J_{s}$. Therefore, contrary to the assumption in (9)-(12), the salinity concentrations $C_{r}$ and $C_{m}$ do not remain constant along the membrane module. This mainly produces a spatial variation of the flow rates, salinity concentrations, pressure losses and hydraulic pressure difference along the membrane, which results in a reduction of the membrane module power output. These variations are formulated by considering that the membrane of area $A_{m e m}$ is divided into $n$ segments of equal area and length $\Delta x$, as follows.

The $k$-th and $(k+1)$-th segments are shown in Fig. 3 . Suppose that the following set of variables are known at the $k$-th segment: permeated flux $J_{w}$, reverse salt flux $J_{s}$, cross-flow rate $Q_{j}$, salinity concentration $C_{j}$, water crossflow velocity $v_{j}$, dimensionless friction factor $f_{j}$, hydraulic diameter $d_{h j}$, water density $\rho_{j}$, membrane length $L$ and hydraulic pressure difference $\Delta P_{h}$. Hence, the water crossflow $Q_{j}$, salinity concentration $C_{j}$ and the hydraulic pressure drop $\Delta P_{h}$ at the $(k+1)$-th segment can be calculated from (17)-(21), respectively. In these formulations $j=r, m$ for the fresh and salt water bodies, respectively. In addition, in (21) the term in brackets represents the hydraulic pressure losses at the $k$-th segment. The friction factor $f_{j}$ for the fresh and salty water in (21) must be computed from (22), where the term between parentheses corresponds to the Reynold's number. $\gamma_{j}$ and $v_{j}$ are the dynamic viscosity and water cross-flow velocity, respectively. $d_{h j}$ represents the internal (external) hydraulic diameter of a single hollow fiber of the hollow fiber membrane module. Lastly, $\rho_{r}\left(1000 \mathrm{~kg} / \mathrm{m}^{3}\right)$ and $\rho_{m}\left(1027 \mathrm{~kg} / \mathrm{m}^{3}\right)$ are the fresh and salty water bodies densities, respectively.

Note that the concentration polarization $\Delta C_{p o l}$ can be considered into the assessment of the spatial variations along a membrane module. For this purpose, the expressions (9)-(15) and (17)-(21) are recursively applied for each $k$-th segment, as explained in the Algorithm 1 given in Table I.

$$
\begin{gathered}
Q_{r(k+1)}=Q_{r(k)}-J_{w(k)} A_{m e m} / n \\
Q_{m(k+1)}=Q_{m(k)}+J_{w(k)} A_{m e m} / n \\
C_{r(k+1)}=\frac{C_{r(k)} Q_{r(k)}+J_{s(k)} A_{m e m} / n}{Q_{r(k+1)}} \\
C_{m(k+1)}=\frac{C_{m(k)} Q_{m(k)}-J_{s(k)} A_{m e m} / n}{Q_{m(k+1)}} \\
\Delta P_{h(k+1)}=\Delta P_{h(k)}-\frac{L}{2 n}\left(\frac{\rho_{m} f_{m(k)} v_{m(k)}^{2}}{d_{h m}}-\frac{\rho_{r} f_{r(k)} v_{r(k)}^{2}}{d_{h r}}\right) \\
f_{j(k)}=6.23\left(\rho_{j} v_{j(k)} d_{h j} / \gamma_{j}\right)^{-0.3} ; j=r, m
\end{gathered}
$$

Once spatial variations and concentration polarization effects are computed by means of Algorithm 1, the power density of the membrane module can be estimated from (23). Accordingly, the power output of the total amount $N_{\text {mod }}$ of membrane modules is formulated as in (24).

$$
\begin{gathered}
W_{a v g}=\frac{1}{L} \sum_{k=1}^{n} A \cdot\left[\Delta \pi_{p o l(k)}-\Delta P_{h(k)}\right] \cdot \Delta P_{h(k)} \cdot \Delta x \\
P_{s v p}=W_{a v g} A_{m e m} N_{m o d}
\end{gathered}
$$

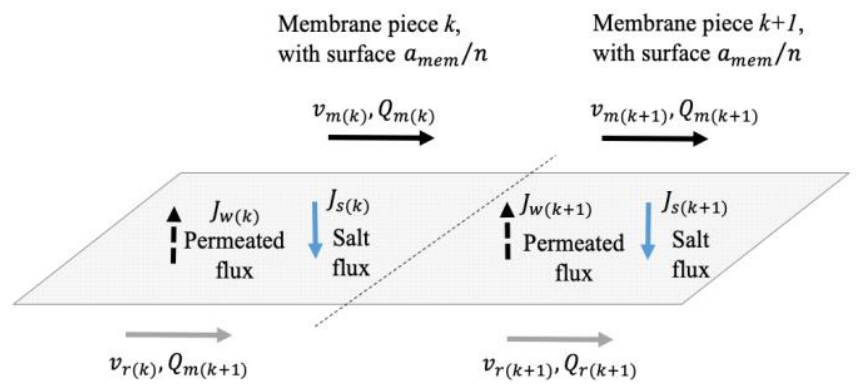

Fig. 3. Spatial variations in flow rates, concentrations and hydraulic pressures along the membrane.

TABLE I

ALGORITHM 1: FOR SPATIAL VARIATIONS AND POLARIZATION

Step 1. Specify the known value of the salinity concentrations $C_{r(1)}$ and $C_{m(1)}$, as well as the cross flux velocities $v_{r(1)}$ and $v_{m(1)}$ at the inlet of the fresh and salt water bins. In this work those values were set as $C_{r(1)}=0 \mathrm{~g} / \mathrm{l}, C_{m(1)}=35 \mathrm{~g} / \mathrm{l}$, and $v_{r(1)}=v_{m(1)}=0.133 \mathrm{~m} / \mathrm{s}$.

Step 2. Set $k=1$.

Step 3. Solve $\Delta C_{\text {pol }(k)}$ from (10) by using a numerical method or solver for the solution of nonlinear equations.

Step 4. Compute $\Delta \pi_{p o l(k),} J_{w(k)}$ and $J_{s(k)}$ by using (13)(14), and (16), respectively.

Step 5. Compute the cross-flow rate $Q_{j(k)}$ as $Q_{j(k)}=A_{j}$ $v_{j(k)}($ for $j=r, m)$, where $A_{j}$ represents the effective area for the fresh and salty water cross-flow. $v_{j(k)}$ is the known water cross flux velocity at the $k$-th segment. Then compute the friction factor $f_{j}$ by using (22).

Step 6. The values of $Q_{j(k+1),} C_{j(k+1)}($ for $j=r, m)$ and $\Delta P_{h(k+1)}$ are computed from (17)-(21). Also, compute $\Delta C_{\text {pol }(k+1)}$ as $\Delta C_{\text {pol }(k+1)}=C_{m(k+1)}-C_{r(k+1)}$

Step 7. If $k<n$, return the values $Q_{j(k)}, C_{j(k)}$ and $\Delta C_{\text {pol }(k)}$ to Step 3 and then set $k=k+1$. Else, the spatial variations and concentration polarization effects along the membrane module have been computed and the algorithm ENDS. 


\section{Membrane modules net power output model considering hydraulic losses}

The hydraulic system is outlined in Fig. 4. The hydraulic system losses reduce the efficiency of the salinity gradient energy conversion. These losses should be considered for the accurate estimation of the membrane modules net power output $P_{\text {net. }}$. For this purpose, the hydraulic losses are reflected to the total power output $P_{\text {svp }}$, as given by (25), where $P_{b p}, P_{r p}$ and $P_{m p}$ represent the power consumptions of the booster, fresh and salty water pumping systems, respectively. The powers $P_{r p}$ and $P_{m p}$ are formulated by (26) and (27), respectively. The variables $Q_{r}$ and $Q_{m}$ are the flows at the fresh and salty water inlet of the membrane module, respectively. Furthermore, $p_{r p u}, p_{r f}$ and $p_{r d}$ are the known pressure drops produced along the fresh water feeder pipe, inside the corresponding filter and along the pipe segment connecting this filter with the membrane modules inlet, respectively (see Fig. 4). Similarly, $p_{m p u}$ and $p_{m f}$ are the pressure drops along the salty water feeder pipe and inside the corresponding filter. $\eta_{r p}$ (resp. $\eta_{m p}$ ) is the efficiency of the fresh (resp. salty) water pump.

Lastly, the boost pump alleviates the remaining pressure drop that is not compensated by the pressure exchanger. The corresponding power consumption $P_{b p}$ is given by (28). In this case, $\eta_{p x}$ and $\eta_{b p}$ are the pressure exchanger and the booster pump efficiencies, respectively, $p_{m d}$ is the pressure drop from the booster pump output to the membrane salty water inlet.

Note that (25) provides an estimation of the membrane modules power output considering the concentration polarization, spatial variation and the hydraulic system losses that affect the overall efficiency of the PRO generation plant.

$$
\begin{gathered}
P_{n e t}=P_{s v p}-\left(P_{r p}+P_{m p}+P_{b p}\right) \\
P_{r p}=\frac{\left(p_{r p u}+p_{r f}+p_{r d}\right)\left(Q_{r} N_{m o d}\right)}{n_{r p}} \\
P_{m p}=\frac{\left(p_{m p u}+p_{m f}\right)\left(Q_{m} N_{m o d}\right)}{n_{m p}} \\
P_{b p}=\frac{\left(p_{m d}+\Delta P_{h}\left(1-n_{p x}\right)\right)\left(Q_{m} N_{m o d}\right)}{n_{b p}}
\end{gathered}
$$

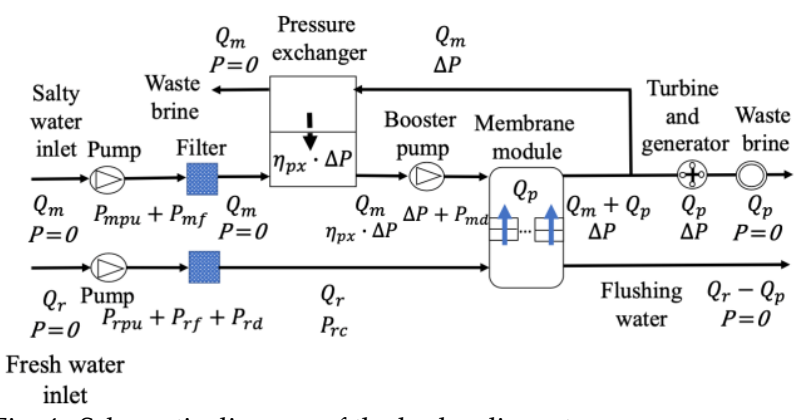

\section{E. Turbine mechanical power output model}

The turbine transduces the total power output $P_{\text {Tmem }}$ of the membrane modules to mechanical power $P_{\text {mech }}$. In order to be able of disclosing the effects of the salinity concentration polarization, spatial variations and hydraulic losses on the complex power output of the PRO generation plant, either $P_{i d}, P_{p o l}, P_{s v p}$ or $P_{n e t}$ evaluated from (8), (15), (24) and (25), respectively, may be set as $P_{\text {Tmem. }}$.

The power transduction performed by the turbine can be expressed in terms of the efficiency $\eta_{t u r}$, as given by (29).

$$
P_{\text {mech }}=\eta_{\text {tur }} P_{\text {Tmem }}
$$

\section{F. Electric generator complex power output model}

In order to make the PRO mechanism attractive for electric power production at a commercial level, most of the existing researches have focussed their attention on the improvement of the membrane technologies. The electric generator technology used in laboratory prototypes and pilot plants for PRO power generation, however, has not been described and discussed in detail [6-13]. Among different electric generator available technologies, the induction machine is an electric generator of small size, low weight, low unit and maintenance costs, better stability and self-protection under fault conditions [14]. This generator can operate in isolated and connected to the grid modes; thus, being potentially useful for microgrid applications. Accordingly, it has been widely used for renewable electricity generation. For example, the induction generator is used to build up commercial wind power generators with rate nominals in a range from 1.0 to $10 \mathrm{MW}$ [15]. This generator technology may also be of potential use for mini-hydraulic power plants [16,17].

The aforementioned induction generator capacities and applications agree with those corresponding to the Statkraft project for electricity generation based on the PRO mechanism [18]. Accordingly, the induction generator is considered in this work to perform the transduction of the turbine mechanical power output into electrical power. For the purpose of this work, the steadystate model of that generator is given below. Certainly, there are other technologies of higher efficiency for low power level applications, e.g. the permanent magnet generator $[19,20]$. The authors are currently addressing the models of those technologies in the context of this work.

A method for analysing the steady-state performance of the three-phase induction machine under unbalanced voltages by using the symmetrical components theory is proposed in [21]. Based on this method and bearing in mind that the stator windings of the induction machine are typically connected in a delta or ungrounded wye connection, the sequence line-to-neutral equivalent circuit of the three-phase induction machine given in Fig. 5 is

Fig. 4. Schematic diagram of the hydraulic system. 
proposed in [22]. Fig. 5 represents both the positive and negative sequence circuits of the machine. The only difference between both sequence circuits is the load resistance $R_{L i}$ used for considering the power transferred to the shaft, which depends on the induction machine sequence slip si as given by (30). In (30) the subscript $i$ takes values of 1 and 2 to denote the positive and negative sequences, respectively. The parameters $R_{s}, R_{r}, X_{s}$ and $X_{r}$ represent the resistance $(R)$ and reactance $(X)$ of the stator (s) windings and rotor $(r)$ of the machine, respectively. The positive and negative sequence slips $s_{1}$ and $s_{2}$ are given by (31) and (32), respectively, where $n_{s}$ and $n$ are the synchronous and rotor speed, respectively.

$$
\begin{gathered}
R_{L i}=\left(1-s_{i}\right) / s_{i} \\
s_{1}=\left(n_{s}-n\right) / n_{s} \\
s_{2}=2-s_{1}
\end{gathered}
$$

By applying a series-parallel impedance reduction to the sequence circuit shown in Fig. 5, the equivalent sequence impedance $Z_{\text {eqi }}$ seen from the stator terminals $L-N$ is given by (33). Considering the line-to-line phasor voltages $V_{\alpha}$ (for $\alpha=a, b, c)$ in the phases reference frame at the machine terminals known, the sequence line-to-neutral voltages $V_{L N i}$ can be computed from (34). In (34), $\boldsymbol{A}_{\text {s }}$ is the wellknown symmetrical component transformation matrix and $T_{s}$ is a diagonal matrix $\operatorname{diag}\left(T_{s}\right)=\left[1, t, t^{*}\right]$ that transforms line-to-line voltages to line-to-neutral voltages, where $t=1 / \sqrt{3} \measuredangle-30^{\circ}$. Now, according to the Ohm's law, the stator sequence currents $\boldsymbol{I}_{s i}$ are formulated by dividing $\boldsymbol{V}_{L N i}$ by $\boldsymbol{Z}_{\text {eqi }}$, as given in (35). The rotor sequence currents $\boldsymbol{I}_{r i}$ can be obtained by applying the current division rule and are given in (36). Based on the sequence currents $\boldsymbol{I}_{s i}$, the machine input current phasors $\boldsymbol{I}_{\alpha}$ can be readily obtained from (37), where the zero-sequence current must be considered as zero (i.e. $\boldsymbol{I}_{\mathrm{s} 0}=0$ ).

The model sought for the evaluation of the complex power output at the machine terminals is as follows. The per phase complex (active $P_{\alpha}$ plus reactive $Q_{\alpha}$ ) power output $S_{\alpha}$ at the machine terminals can be assessed from (38), where $I_{\alpha}$ is the vector of current phasors obtained from (37). Whereas the equivalent line-to-neutral phasor voltages $V_{L N \alpha}$ in the $a b c$ reference frame are readily obtained from the sequence line-to-neutral voltages $V_{L N i}$ computed from (34), as given by (39). Lastly, the total complex power output $S_{3 \phi}$ is computed from (40).

$$
\begin{gathered}
\boldsymbol{Z}_{e q i}=R_{s}+j X_{s}+\frac{\left(j X_{m}\right)\left[R_{r}+\left(\frac{1-s_{i}}{s_{i}}\right)+j X_{r}\right]}{R_{r}+\left(\frac{1-s_{i}}{s_{i}}\right)+j\left(X_{m}+X_{r}\right)} \\
{\left[\boldsymbol{V}_{L N}\right]_{0,1,2}=[T] \cdot[A]^{-1} \cdot\left[\boldsymbol{V}_{L L}\right]_{a b c}} \\
\boldsymbol{I}_{s i}=\frac{\boldsymbol{V}_{L N i}\left[j\left(X_{r}+X_{m}\right)+\left(\frac{R_{r}}{s_{i}}\right)\right]}{j X_{m}\left(j X_{r}+\frac{R_{r}}{S_{i}}\right)+\left(R_{s}+j X_{s}\right)\left[j\left(X_{r}+X_{m}\right)+\left(\frac{R_{r}}{s_{i}}\right)\right]}
\end{gathered}
$$

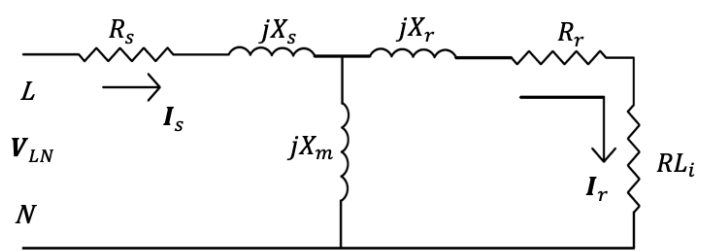

Fig. 5. Generator positive and negative sequence circuit.

$$
\begin{gathered}
\boldsymbol{I}_{r i}=\frac{j X_{m}}{j\left(X_{r}+X_{m}\right)+R_{r} / s_{i}} \boldsymbol{I}_{s i} \\
{[\boldsymbol{I}]_{a b c}=[A]\left[\boldsymbol{I}_{s}\right]_{0,1,2}} \\
\boldsymbol{S}_{\alpha}=P_{a}+j Q_{a}=\boldsymbol{V}_{L N \alpha} \boldsymbol{I}_{\alpha}^{*} \\
{\left[\boldsymbol{V}_{L N}\right]_{a b c}=[A]\left[\boldsymbol{V}_{L N}\right]_{0,1,2}} \\
\boldsymbol{S}_{3 \phi}=P_{3 \phi}+j Q_{3 \phi}=\sum_{\forall \alpha=a, b, c} \boldsymbol{S}_{\boldsymbol{\alpha}}
\end{gathered}
$$

The mathematical expressions (37), (38), (39) and (40) are useful to assess the $a b c$ currents and complex power outputs when the positive sequence slip $s_{1}$ of the machine is already known, as proposed in [22]. In the context of this work, however, $s_{1}$ is not known in advance but can be computed as follows.

The power balance between the turbine mechanical power output $P_{\text {mech }}$ and the power converted in the machine rotor $P_{R}$ must be satisfied. Neglecting rotational losses, that power balance is stated by the nonlinear equation (41), where $P_{R}$ is formulated in (42). Note that the relationship between $s_{1}$ and $s_{2}$ given by (32) allows expressing $P_{R}$ only in terms of the positive sequence slip $s_{1}$. In this way, the value of $s_{1}$ sought can be assessed from the solution of (41).

$$
\begin{gathered}
P_{\text {ind }}=P_{\text {mech }}+P_{R}=0 \\
P_{R}=3\left|\boldsymbol{I}_{r 1}\right|^{2}\left(\frac{1-s_{1}}{s_{1}}\right) R_{r}+3\left|\boldsymbol{I}_{r 2}\right|^{2}\left(\frac{s_{1}-1}{2-s_{1}}\right) R_{r}
\end{gathered}
$$

In order to solve (41), however, an initial condition $s_{1}^{0}$ of the slip $s_{1}$ is required. For this purpose, the quadratic equation (43) is formulated by considering the positive sequence equivalent circuit (see Fig. 5), neglecting the magnetization current and equating the power consumed by $R_{L 1}$ and $P_{\text {mech. }}$. The constant coefficients in (43) are as given in (44). The solution of (43) is directly obtained from (45), which yields the rotor load resistances $R_{L 1 k}$ (for $k=1,2$ ) corresponding to two different positive sequence slips $s_{1 k}^{0}$. According to (30), these slips can be computed form (46) and the value of the initial slip $s_{1}^{0}$ sought can be directly obtained as indicated by (47). 


$$
\begin{aligned}
& A_{E G} R_{L 1}^{2}+B_{E G} R_{L 1}+C_{E G}=0 \\
& A_{E G}=P_{\text {mech }}, B_{E G}=2 P_{\text {mech }}\left(R_{r}+R_{S}\right)-V_{L N 1}^{2} \text {, } \\
& C_{E G}=P_{\text {mech }}\left(X_{S}+X_{r}\right)^{2}-V_{L N 1}^{2}\left(R_{r}+R_{s}\right) \\
& +P_{\text {mech }}\left(R_{r}+R_{s}\right)^{2} \\
& R_{L 1 k}=\frac{-B_{E G} \pm \sqrt{B_{E G}^{2}-4 A_{E G} C_{E G}}}{2 A_{E G}} \\
& s_{1 k}^{0}=R_{r} /\left(R_{r}+R_{L 1 k}\right) \\
& s_{1}^{0}=\min \left\{\left|s_{1 k}^{0}\right|\right\}
\end{aligned}
$$

\section{ASSEMBLED PRO PLANT MODEL FOR EVALUATING THE} COMPLEX POWER OUTPUT

In this section the assembling of the PRO plant model for evaluating the complex power output is performed based on the models of the PRO plant components given in Section II. The assembling of the model and the PRO plant complex power output evaluation are described in terms of the procedure depicted in Table II. This model and procedure allow evaluating the PRO plant complex power output as a function of the salinity concentrations $C_{m}$ and $C_{r}$ of the salty and fresh water bodies, respectively, the hydraulic pressure $\Delta P_{h}$ applied at the salty water bin inlet and the line-to-line phasor voltages $V_{\alpha}$ (for $\alpha=a, b, c$ ) at the generator terminals. That procedure assumes that the physical parameters of the salty and fresh water, as well as of the PRO plant components are available for the evaluation of the PRO plant complex power output. Therefore, the proposal of this work has been fulfilled.

\section{NUMERICAL RESULTS}

In this section a PRO generation plant of an installed capacity of $7.5 \mathrm{~kW}$ is considered. In order to meet this power installed capacity 10 membrane modules covering a total area surface of $2220 \mathrm{~m}^{2}$ are considered. Each module is built up based on a hollow fiber membrane of an expected power density of $4.1 \mathrm{~W} / \mathrm{m}^{2}$. The parameters, geometry and operating conditions of the membrane are given in Table III. The salty and fresh water properties are given in Table IV. The hydraulic system specifications and the turbine efficiency are given in Table V. Lastly, the rated power of the three-phase electric generator matches the installed capacity of the PRO generation plant and operates at a balanced line to line voltage level of $480 \mathrm{~V}$. The specific parameters of the electric generator are given in Table VI.

The aforementioned PRO generation plant is represented by the model assembled in Section III. The procedure given in Table II is used to evaluate its complex power output for hydraulic pressure differences $\Delta P_{h}$ at the salty water bins inlet in the range defined by $\Delta P_{h R}=[250 \mathrm{kPa}, 2750 \mathrm{kPa}]$. The numerical results obtained under these operating conditions are as follows.
I ABLE II

ALGORITHM 2: ASSEMBLING THE PRO PLANT MODEL FOR EVALUATING THE COMPLEX POWER OUTPUT

Step 1. Provide the model inputs. For the evaluation of the complex power output, the PRO plant model has the following four main inputs; 1) The salinity concentration of the salty water $C_{m}, 2$ ) The salinity concentration of the fresh water $C_{r}, 3$ ) The hydraulic pressure $\Delta P_{h}$ applied at the salty water bin inlet and 4) The line-to-line phasor voltages $V_{\alpha}$ $(\alpha=a, b, c)$ at the generator terminals. The values of these parameter must be provided to assess the membrane modules power output, as defined below in Step 2.

Step 2. Evaluation of the membrane modules power output model. The total power output of the membrane modules $P_{\text {Tmem }}$ can be set as either $P_{i d}$, $P_{\text {pol }}, P_{\text {svp }}$ or $P_{\text {net }}$ (see Section II.E). Based on the PRO plant model inputs 1, 2 and 3 defined in Step 1, these power outputs are computed from (8), (15), (24) and (25), respectively.

Step 3. Evaluation of the turbine power output model. The simple turbine model (29) allows considering the membrane modules total power output evaluated at Step 2 to assess the mechanical power $P_{\text {mech }}$ at the electric generator shaft.

Step 4. Evaluation of the generator power output model. Considering the mechanical power $P_{\text {mech }}$ computed at Step 3, the solution of nonlinear equation (41) must be firstly computed to assess the positive sequence slip $S_{1}$. Then, consider the PRO plant model input 4 given in Step 1 to compute the sequence line-to-neutral voltages $V_{L N I}$ from (34). Evaluate the stator sequence currents $I_{s i}$ from (35). Use (37) and (39) to assess the current phasors $\boldsymbol{I}_{\alpha}$ and the line to neutral phasor voltages $V_{L N \alpha}$ in the phase reference frame $(\alpha=a, b, c)$, respectively. Lastly, use the models (38) and (40) to evaluate the per phase $\boldsymbol{S}_{\alpha}$ and three phase $\boldsymbol{S}_{3 \phi}$ complex power output of the electric generator.

Step 5. PRO plant complex power output. The per phase $\boldsymbol{S}_{\alpha}$ and/or three phase $\boldsymbol{S}_{3 \phi}$ complex power output of the electric generator computed at Step 4, can be considered as the PRO plant complex power output. This procedure ENDS.

For the hydraulic pressure differences in the range $\Delta P_{h R}$, the Fig. 6 and 7 show the active and reactive three-phase power output curves of the PRO generation plant. These power output curves of the PRO generation plant were obtained by considering the membrane modules total power output $P_{i d}, P_{p o l}, P_{\text {svp }}$ and $P_{\text {net }}$ assessed from the models (8), (15), (24) and (25), respectively, as pointed out in Step 2 of the procedure given in Table II. 


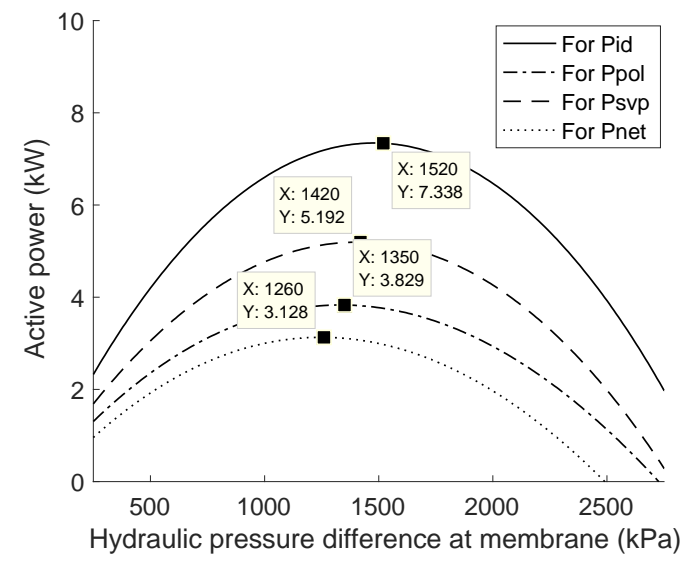

Fig. 6. Active power $P$ as function of hydraulic pressure $\Delta P_{h}$.

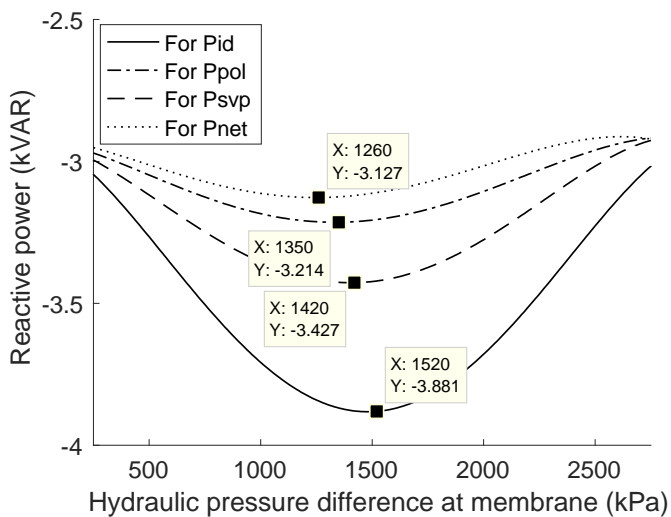

Fig. 7. Reactive power $Q$ as function of hydraulic pressure $\Delta P_{h}$.

Fig. 6 shows that for the pressure differences in the range $\Delta P_{h R}$, the highest active power output curve of the PRO generation plant is obtained when the membrane modules total power output is evaluated from the ideal model (8). According to this power curve, the maximum active power output of the PRO plant is around $7.3 \mathrm{~kW}$, which corresponds to a hydraulic pressure difference about $1520 \mathrm{kPa}$. This maximum power is very close to the installed capacity of the generation plant. It is also noted that the active power density at the generation plant terminals, computed in this work as the maximum total power output divided by the membrane modules total area $\left(2220 \mathrm{~m}^{2}\right)$, is around $3.3 \mathrm{~W} / \mathrm{m}^{2}$. This active power density is around of $1 \mathrm{~W} / \mathrm{m}^{2}$ lower than the expected power density of the membrane $\left(4.1 \mathrm{~W} / \mathrm{m}^{2}\right)$. This difference is due to the efficiency of the turbine and the active power losses inside the electric generator.

When the polarization, spatial variations and the hydraulic system losses are considered to evaluate the membrane modules total power output through the models (15), (24) and (25), the corresponding active power output curves of the PRO plant drastically drop. As clearly shown in Fig. 6, the lowest active power output curve of the PRO plant corresponds to the case where the membrane modules total power output is obtained from (25). The power curve reaches a maximum value of $3.1 \mathrm{~kW}$, which is $50 \%$ lower than the installed capacity of the generation plant. In this case, the active power density is drastically decreased to a value around of $1.4 \mathrm{~W} / \mathrm{m}^{2}$, which
TABLE III

MEMBRANE PARAMETERS

\begin{tabular}{|c|c|c|}
\hline Symbol & Quantity & Unit \\
\hline \multicolumn{3}{|c|}{ Membrane module parameters } \\
\hline$A$ & Water permeability & $\begin{array}{l}1.87 \mathrm{e}-9 \\
m /(s k P a)\end{array}$ \\
\hline$B$ & Salt permeability & $\begin{array}{l}1.11 \mathrm{e}-7 \\
\mathrm{~m} / \mathrm{s}\end{array}$ \\
\hline$S$ & Structure parameter & $6.78 \mathrm{e}-4 \mathrm{~m}$ \\
\hline \multicolumn{3}{|c|}{ Geometry of membrane module } \\
\hline Amem & Surface area & $222 m^{2}$ \\
\hline$L$ & Length concentration & $1.52 \mathrm{~m}$ \\
\hline$A_{r}$ & $\begin{array}{l}\text { Effective area for the } \\
\text { fresh water cross-flow }\end{array}$ & $0.0183 \mathrm{~m}^{2}$ \\
\hline$A_{m}$ & $\begin{array}{l}\text { Effective area for the } \\
\text { salty water cross-flow }\end{array}$ & $0.0358 \mathrm{~m}^{2}$ \\
\hline \multicolumn{3}{|c|}{ Operating conditions } \\
\hline$T$ & Temperature & $297.15 \mathrm{~K}$ \\
\hline$C_{r}$ & $\begin{array}{l}\text { Fresh water } \\
\text { concentration }\end{array}$ & $0 g / l$ \\
\hline$C_{m}$ & $\begin{array}{l}\text { Salty water } \\
\text { concentration }\end{array}$ & $35 \mathrm{~g} / \mathrm{l}$ \\
\hline$v_{r}$ & $\begin{array}{l}\text { Fresh water cross-flow } \\
\text { velocity inlet }\end{array}$ & $0.063 \mathrm{~m} / \mathrm{s}$ \\
\hline$v_{m}$ & $\begin{array}{l}\text { Salty water cross-flow } \\
\text { velocity inlet }\end{array}$ & $0.063 \mathrm{~m} / \mathrm{s}$ \\
\hline
\end{tabular}

TABLE IV

SALTY AND FRESH WATER PROPERTIES

\begin{tabular}{lll}
\hline Symbol & Quantity & Unit \\
\hline$\rho_{r}$ & Fresh water density & $1000 \mathrm{~kg} / \mathrm{m}^{3}$ \\
$\rho_{m}$ & Salty water density & $1027 \mathrm{~kg} / \mathrm{m}^{3}$ \\
$\gamma_{r}$ & Dynamic fresh water & $9.17 \mathrm{e}-4$ \\
& viscosity & $\mathrm{kg} /(\mathrm{m} \mathrm{s})$ \\
$\gamma_{m}$ & Dynamic salty water viscosity & $9.88 \mathrm{e}-4$ \\
& & $\mathrm{~kg} /(\mathrm{m} \mathrm{s})$ \\
$C_{r}$ & Fresh water concentration & $0 \mathrm{~g} / \mathrm{l}$ \\
$C_{m}$ & Salty water concentration & $35 \mathrm{~g} / \mathrm{l}$ \\
\hline
\end{tabular}

TABLE V

HYDRAULIC SYSTEM SPECIFICATIONS

\begin{tabular}{lll}
\hline Symbol & Quantity & Unit \\
\hline$\eta_{r p}, \eta_{m p}, \eta_{b p}$ & Pump efficiency & $77 \%$ \\
$\eta_{p x}$ & Exchanger efficiency & $97 \%$ \\
$P_{j p u}, P_{j f}, P_{j d}$ & Pressure losses & $0 \mathrm{kPa}$ \\
$\eta_{t u r b}$ & Turbine efficiency & $85 \%$ \\
\hline
\end{tabular}

TABLE VI

INDUCTION GENERATOR PARAMETERS

\begin{tabular}{lll}
\hline Symbol & Quantity & Unit \\
\hline$P$ & Power rating & $7.5 \mathrm{~kW}$ \\
$V$ & Operating voltage & $480 \mathrm{~V}$ \\
$R_{r}$ & Rotor resistance & $0.647 \Omega$ \\
$R_{s}$ & Stator resistance & $0.740 \Omega$ \\
$X_{r}$ & Rotor reactance & $2.01 \Omega$ \\
$X_{s}$ & Stator reactance & $1.33 \Omega$ \\
$X_{m}$ & Magnetization & $77.6 \Omega$ \\
& reactance & \\
\hline
\end{tabular}


is approximately $65 \%$ lower than the expected power density of the membrane. The active power densities for the cases considered in Fig. 6 are summarized in column 2 of Table VII. These results corroborate that the polarization, spatial variations and the hydraulic system losses, along with the turbine efficiency and electric generator internal power losses importantly reduce the maximum expected active power output of the PRO generation plant.

The reactive power curves at the PRO generation plant terminals shown in Fig. 7 state that, for the selected electric generator, an important reactive power consumption is expected. Accordingly, under the selected electric power transductor technology, the reactive power compensation should be considered for the integration of the PRO generation plants. The reactive power curves clearly show that the maximum reactive power consumption occurs at the maximum active power production. The reactive power densities, which are computed in a similar way to the active power densities, are summarized in column 3 of Table VII. Note that the reactive power densities almost remain constant. This clearly suggests that the polarization, spatial variations and the hydraulic system losses have not a relevant effect on the reactive power consumption, which may be expected because those phenomena are mainly related to the active power production.

Lastly, the magnitude $I_{a}$ of the line current phasor $I_{a}$ at the PRO generation plant terminals is shown in Fig. 8. The magnitudes $I_{b}$ and $I_{c}$ are very similar to $I_{a}$. Note that the hydraulic pressure differences $\Delta P_{h}$ in the range $\Delta P_{h R}$ produces a maximum value of $I_{a}$ for the membrane modules total power outputs $P_{i d}, P_{\text {pol }}, P_{\text {svp }}$ and $P_{\text {net. }}$. As expected, the maximum value of $I_{a}$ is reached about the same hydraulic pressure difference that produces the maximum active power production (see Fig. 6).

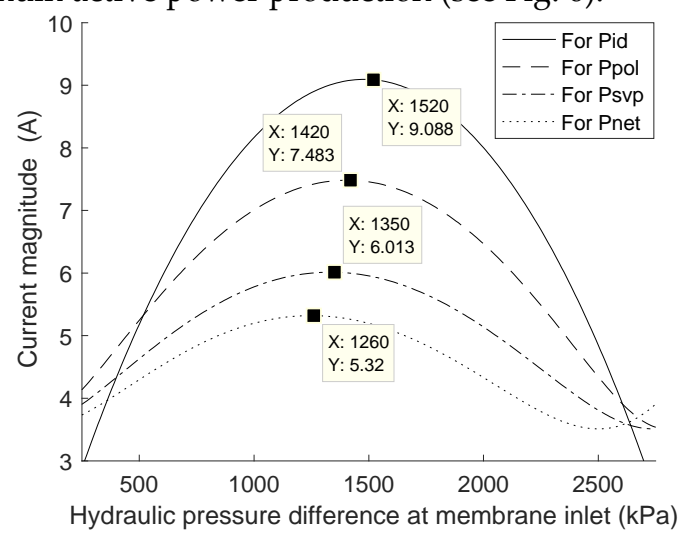

Fig. 8. Magnitude $I_{a}$ of the line current phasor $\boldsymbol{I}_{a}$.

TABLE VII

ACTIVE AND REACTIVE POWER DENSITIES

\begin{tabular}{lll}
\hline $\begin{array}{l}\text { Power } \\
\text { curve }\end{array}$ & $\begin{array}{l}\text { Active power } \\
\text { density }\left(\mathrm{W} / \mathrm{m}^{2}\right)\end{array}$ & $\begin{array}{l}\text { Reactive power } \\
\text { density VAR/ m}\end{array}$ \\
\hline Pid & 3.3 & 1.8 \\
Ppol & 2.9 & 1.5 \\
Psvp & 1.7 & 1.4 \\
Pnet & 1.4 & 1.4 \\
\hline
\end{tabular}

\section{CONCLUSION}

In this paper a mathematical model for evaluating the phasor currents and the complex power at the terminals of a PRO generation plant has been proposed. Based on this model, a suitable procedure to perform that evaluation based on the salinity gradient between the salty and fresh water bodies and the phasor voltages at the electric generator terminals is detailed from first principles. The numerical results show that the active power output and the power density at the PRO plant terminals drastically drop when the concentration polarization and spatial variations phenomena, the hydraulic system efficiencies and the electric generator loses are considered. These results toughen the need of improving the technology of the membranes and the design of the PRO modules, but also reveal the need of increasing the hydraulic system efficiencies and reducing the electric generator loses. The use of the induction generator as power transductor shows that reactive power compensation may be required, which might encourage to looking for another most suitable electric generator technology. In this context, the modular composition of the assembled model can be readily modified and upgraded to consider more detailed and new models of the PRO plant components.

Lastly, the proposal is currently be used to evaluate how the integration of PRO generation plants affects the steadystate performance and operation of electric power networks. The results will be reported in a forthcoming publication.

\section{REFERENCES}

[1] IEO, “International Energy Outlook 2017," Sep. 2017. [Online] Available: $\underline{w w w . e i a . g o v / i e o}$

[2] M. Höök, X. Tang, "Depletion of fossil fuels and anthropogenic climate change: A review," Energy Policy, vol. 52, pp. 797-809, 2013.

[3] IRENA, "Renewable Power Generation Costs in 2017," International Renewable Energy Agency, Abu Dhabi, 2018. [Online] Available: http://www.irena.org/publications

[4] Method and apparatus for generating power utilizing pressureretarded-osmosis, by Sydney Loeb. (1975, September 16). [Online] Available: https://patents.google.com/patent/US3906250A/en

[5] T. D. T. Tran et al., "Design of Housing and Mesh Spacer Supports for Salinity Gradient Hydroelectric Power Generation Using Pressure Retarded Osmosis," in IEEE Conference on Technologies for Sustainability (SusTech), Ogden, UT, 2015, pp. 141-147.

[6] A. P. Straub, A. Deshmukh, M. Elimelech, "Pressure-retarded osmosis for power generation from salinity gradients: is it viable?," Energy \& Environmental Science, vol. 9, pp. 31-48, 2016.

[7] K. Touati, F. Tadeo, S. Ho Chae, J. Ha Kim, O. A. Silva, "Water and salt flux in Pressure Retarded Osmosis" in Pressure retarded osmosis as renewable energy generation and recovery. Academic Press of Elsevier, 2017, ch. 2, pp. 55-94.

[8] J. Maisonneuve and P. Pillay, "Pressure-retarded osmotic power for remote communities in Quebec," in IEEE PES General Meeting Conference \& Exposition, National Harbor, MD, 2014, pp. 1-5.

[9] T. Thorsen, T. Holt, "The potential for power production from salinity gradients by pressure retarded osmosis," Journal of Membrane Science, vol. 335, pp. 103-110, 2009. 
[10] A. Achilli, T. Y. Cath, A. E. Childress, "Power generation with pressure retarded osmosis: An experimental and theoretical investigation," Journal of Membrane Science, vol. 343, pp. 42-52, 2009.

[11] F. Naguib, J. Maisonneuve, C. Laflamme, P. Pillay, “Modelling pressure-retarded osmotic power in commercial length membranes," Renewable Energy, vol. 76, pp. 619-627, 2015.

[12] J. Maisonneuve, P. Pillay, C. B. Laflamme, "Pressure-retarded osmotic power system model considering non-ideal effects," Renewable Energy, vol. 75, pp. 416-424, 2015.

[13] J. Maisonneuve, C. B. Laflamme, P. Pillay, "Experimental investigation of pressure retarded osmosis for renewable energy conversion: Towards increased net power," Applied Energy, vol. 164, pp. 425-435, 2016.

[14] H. P. Tiwari , J. K. Diwedi, "Minimum capacitance requirement for self-excited induction generator," National Power Systems Conference, 2002, vol. 2, pp. 5-10.

[15] Siemens. (2019). Visible body: "GD Wind generators from Siemens". [Online] Available: https://www.industry.siemens.com/verticals/global/en/windturbine/power-generation/Pages/wind-generators-gd.aspx

[16] N. P. A. Smith, "Induction generators for stand-alone microhydro systems," in Proc. Int. Conf. on Power Electronics, Drives and Energy Systems for Industrial Growth, New Delhi, India, 1996, vol. 2, pp. 669-673.

[17] C. P. Ion and C. Marinescu, "Micro hydro power plant with three-phase induction generator feeding single-phase consumers," in $4^{\text {th }}$ International Conference on Power Engineering, Energy and Electric Drives, Istanbul, 2013, vol. 2, pp. 1211-1216.

[18] O. S. Skramesto, S. E. Skilhagen, W. K. Nielsen, "Power Production based on Osmotic Pressure," Statkraft, Norway. [Online] Available:

https://www.statkraft.com/globalassets/old-contains-the-oldfolder-structure/documents/waterpower xvi _power_production_based_on_osmotic_pressure_tcm214795.pdf

[19] H. Gavrila, V. Manescu, G. Paltanea, G. Scutaru, I. Peter, "New Trends in Energy Efficient Electrical Machines," Procedia Engineering, vol. 181, pp. 568-574, 2017.

[20] M. J. Melfi, S. Evon and R. McElveen, "Induction versus permanent magnet motors," in IEEE Industry Applications Magazine, vol. 15, no. 6, pp. 28-35, Nov.-Dec., 2009.

[21] J. E. Brown, O. I. Butler, "A general method of analysis of threephase induction motors with asymmetrical primary connections," Proceedings of the IEE - Part II: Power Engineering, vol. 100, no. 73, pp. 25-34, February, 1953.

[22] W. H. Kersting, W. H. Phillips "Phase Frame Analysis of the Effects of Voltage Unbalance on Induction Machines," IEEE Trans. on industry applications, vol. 33, no. 2, pp. 415-420, MarchApril, 1997 